\title{
Assessing Generic and Domain- Specific Academic Competencies in Higher Education
}

\author{
Olga Zlatkin-Troitschanskaia, Hans Anand Pant, and Samuel Greiff
}

According to the German Council of Science and Humanities (2015), academic education in the $21^{\text {st }}$ century comprises three central dimensions: scientific disciplines, preparation for the labor market, and personal development. This understanding coincides with a holistic notion of competence in educational research (Weinert 2001). The focus of higher education is therefore placed not only on the acquisition of domain-specific knowledge (e.g., in medicine or economics) but also, and perhaps even more importantly, on the development and promotion of so-called generic (interdisciplinary) skills (e.g., problem solving, critical thinking, teamwork), which, according to current surveys amongst employers, are increasingly gaining significance in the $21^{\text {st }}$ century. A competence portfolio of this sort, acquired over the course of academic studies, is crucial for all professionals and engaged citizens and allows for lifelong learning, which is necessary in this ever-changing age of information (NRC 2011).

Despite this sociopolitical consensus and the growing competence orientation (in the context of the Bologna reform), only limited evidence-based insights existed up until the past decade, particularly regarding the learning outcomes of higher education students and graduates. This politically and practically volatile deficit is primarily due to a lack of theoretical-conceptual models allowing for an empirically differentiated and precise description and operationalization of skills and knowledge to-be-acquired over the course of study. There was also a lack of suitable test instruments and measurement methods for an objective, reliable, and valid assessment of knowledge, skills acquisition, and learning outcomes. An analysis of the international state of research in 2010 and re-analyses between 2015 and 2017 regarding the assessment of student competencies documented considerable systematic deficits in higher education assessment practice and competency research, particularly regarding the current challenges in competence orientation (Zlatkin-Troitschanskaia et al. 2016, 2017a). In fact, even established examination and evaluation practices over the course of study in the form of certificates and grades do not reveal much about the competencies actually acquired by students and are only marginally comparable across Germany or with other countries (German Council of Science and Humanities 2012).

For this reason, the Germany-wide research initiative Modeling and Measuring Competencies in Higher Education (KoKoHs) was established in 2011 by the Federal Ministry of Education and Research. In $70 \mathrm{KoKoHs}$ projects, theoretical-conceptual competence models and corresponding measurement instruments were developed and successfully validated for selected large study domains (e.g., economics, STEM, teacher education, medicine) in order to differentiate, reliably describe, and assess the competencies of students in different phases of higher education (freshmen, undergraduates, graduates). So far, more than 100 innovative video-, computer-, and simulation-based test instruments have been validated across Germany at more than 250 universities with over 65,000 bachelor's and master's students. The assessments focused on both domain-specific competencies (e.g., domain-specific knowledge) and generic skills (e.g., critical thinking), which students and graduates should acquire over the course of their studies and which employers and other stakeholders expect in view of the current professional and social requirements of the $21^{\text {st }}$ century. With the measurement instruments developed in KoKoHs, the knowledge and skill level of students and graduates can be assessed in an objective, reliable, and valid manner (Zlatkin-Troitschanskaia et al. 2017b). The data provide important, evidence-based insights into knowledge and skill acquisition and their influences, that is, how different competence facets can be effectively promoted over the course of study.

The presented findings are the result of research conducted in 16 cross-institutional collaborative projects throughout Germany that are highly representative of research on competencies in higher education. Based on newly developed domain-specific and generic competence models and corresponding test instruments, the KoKoHs projects carry out in-depth validation and development of 
new methods to validly assess competencies in higher education. The contributions serve as examples of competence and competence assessment in the respective areas and domains.

Overall, this special issue in the German Journal of Educational Psychology is composed of five articles, all of which are closely connected to the overarching aim of KoKoHs. Two of the articles in this special issue present current work from the area of generic competencies. In the two projects presented therein, innovative methods were developed and comprehensively validated for the assessment of different facets of generic competencies.

The first article by Gabriele Steuer and colleagues focuses on the assessment and analysis of conditional motivational regulation strategy knowledge as an aspect of undergraduates' self-regulated learning competencies. For undergraduates, motivational regulation represents a daily challenge in their studies. The authors highlight the crucial role of conditional strategy knowledge and explain which motivational regulation strategies are appropriate for which specific motivational problem. In this study, the authors used a newly developed situational judgement test for assessing strategy knowledge and revealed moderately positive correlations between knowledge and motivational regulation and the students' efforts on the behavioral level.

In the second contribution by Carolin Hahnel and colleagues, the impact of cognitive load on university students' comprehension of multiple documents is investigated using a newly developed technology-based assessment. In this study, perceived task difficulty and mental effort were analyzed by examining task characteristics, students' characteristics, and processing behavior. When considering perceived difficulty and mental effort as covariates, cognitive load was incrementally predictive of students' comprehension of multiple documents.

The second part of the special issue presents three contributions on domain-specific competencies within two study domains, business $\sigma$ economics and medicine.

The article by Olga Zlatkin-Troitschanskaia and colleagues outlines the results from a Germany-wide representative study that assessed the economic knowledge and understanding of beginning undergraduate students using a newly developed and validated domain-specific test. For validation purposes, an intelligence test was used to assess additional student characteristics as well as the students' general cognitive abilities, and the interrelations between these variables were examined. The results confirm the psychometric quality of the new test and show how this test can be used effectively in regular university practice.

The article by Susan Seeber and colleagues focuses on an interesting facet of economic competencies: Competencies in sustainability management are assessed using a newly developed computer-based performance assessment. In this paper, the theoretically expected dimensions of a competence model for sustainability management are empirically examined. The study results are in line with expectations, revealing that the types of knowledge (declarative vs. schematic and strategic knowledge) addressed by different assessment formats and content requirements can be presented in two disjunct dimensions: declarative knowledge in the field of business administration and sustainability from a social perspective on the one hand and sustainability management on the other.

In the last article of this special issue, written by Kirstin Schick and colleagues, findings on medical students' acquisition of communication skills are presented. The study adapted and comprehensively validated the internationally established Kalamazoo Communication Skills Assessment (KCSA) for use in Germany, which includes a student self-assessment (KCSAFd-self), an assessment by patients (KCSAFd-sPat), and a video-assessment by trained raters (KCSAFd-video). The analyses identified a twofactor model that distinguishes between interpersonal and conversational competence and shows practical implications for the development of medical students' communicative competencies during their studies and their subsequent clinical practice years.

Overall, the five articles in this special issue cover fundamental research on generic and domain-specific competencies. The presented articles each focus on advances in both of these areas, representing the breadth and depth of cutting-edge research in higher education assessment. In their entity, they provide insights into indepth validation studies, technology-based performance assessments, and other measurement innovations. All in all, this special issue shows new promising perspectives for educational-psychological research and for assessing generic and domain-specific academic competencies in higher education.

We would like to thank everyone involved in making this special issue possible, particularly the authors, reviewers, and proofreaders.

Mainz, Berlin, Luxemburg April 2019

\section{References}

National Research Council. (2011). Assessing 21st Century Skills: Summary of a Workshop. Washington, DC: The National Academies Press.

Weinert, F. E. (2001). Concept of competence: A conceptual clarification. In D. S. Rychen \& L. H. Salganik (Eds.), Defining and selecting key competencies (pp. 45 - 65). Seattle: Hogrefe \& Huber. Wissenschaftsrat (2012). Prüfungsnoten an Hochschulen im Prüfungsjahr 2010. Arbeitsbericht mit einem Wissenschaftspolitischen Kommentar des Wissenschaftsrats. Available 
from: http://www.wissenschaftsrat.de/download/archiv/262712.pdf.

Wissenschaftsrat (2015). Empfehlungen zum Verhältnis von Hochschulbildung und Arbeitsmarkt - Zweiter Teil der Empfehlungen zur Qualifizierung von Fachkräften vor dem Hintergrund des demographischen Wandels. Available from: http://www.wissen schaftsrat.de/download/archiv/4925-15.pdf.

Zlatkin-Troitschanskaia, O., Pant, H. A., Kuhn, C., Toepper, M., \& Lautenbach, C. (2016). Messung akademisch vermittelter Kompetenzen von Studierenden und Hochschulabsolventen. Ein Überblick zum nationalen und internationalen Forschungsstand. Wiesbaden: Springer VS.

Zlatkin-Troitschanskaia, O., Pant, H. A., Lautenbach, C., Molerov, D., Toepper, M., \& Brückner, S. (2017a). Modeling and Measuring
Competencies in Higher Education: Approaches to Challenges in Higher Education Policy and Practice. Wiesbaden: Springer VS.

Zlatkin-Troitschanskaia, O., Pant, H. A., Toepper, M., Lautenbach, C. \& Molerov, D. (2017b). Valid Competency Assessment in Higher Education: Framework, Results, and Further Perspectives of the German Research Program KoKoHs. AERA Open, 3(1), 1 - 22.

\section{Prof. Dr. Olga Zlatkin-Troitschanskaia}

Department of Business and Economics Education

Johannes Gutenberg University Mainz

Jakob-Welder-Weg 9

55099 Mainz

Istroitschanskaia@uni-mainz.de 